\title{
Desempenho e características bioquímicas de leitões submetidos a dietas com aditivos probióticos, prebióticos, simbióticos e antibióticos
}

\author{
[Performance and biochemical parameters of piglets and the use of alternative \\ additives as antibiotic replacement]
}

\author{
M.L. Névoa ${ }^{1}$, J.G. Caramori Júnior ${ }^{1}$, G.S.S. Corrêa ${ }^{1}$, V.M. Arantes ${ }^{1}$, R. Kamimura ${ }^{2}$, \\ F.C. Gonçalves ${ }^{3}$, M.S.F. Oliveira ${ }^{1,5}$, A.L. Santos ${ }^{4}$, R.P. Nalon ${ }^{1}$ \\ ${ }^{1}$ Universidade Federal de Mato Grosso - Cuiabá, MT \\ ${ }^{2}$ Universidade Federal de Goiânia - Goiânia, GO \\ ${ }^{3}$ Universidade Federal de Uberlândia - Uberlândia, MG \\ ${ }^{4}$ Universidade Federal de Mato Grosso - Rondonópolis, MT \\ ${ }^{5}$ Bolsista da Capes
}

\begin{abstract}
RESUMO
Avaliaram-se o desempenho e as características bioquímicas de leitões desmamados, utilizando-se aditivos alternativos em substituição aos antibióticos. Foram utilizados 480 leitões machos, distribuídos em delineamento inteiramente ao acaso, composto por cinco tratamentos. A ração foi à base de milho, farelo de soja e um núcleo comercial para leitões. Os tratamentos consistiram em T1: ração sem aditivos, T2: dieta basal com antibiótico, T3: dieta basal com adição de prebiótico, T4: dieta basal com adição de probiótico e T5: dieta basal com adição de simbiótico. Foram avaliados peso corporal, ganho de peso, consumo de ração e conversão alimentar. Em 50 amostras de sangue de leitões, sendo 10 amostras de cada tratamento, avaliaram-se as concentrações séricas de proteínas totais, de albumina e globulina, a relação albumina:globulina e a fosfatase alcalina, creatinina, alanina aminotransferase, aspartato aminotransferase, gama- glutamiltransferase, colesterol, ureia, cálcio e fósforo e a relação cálcio:fósforo. A substituição de antibióticos por aditivos alternativos não influenciou o desempenho nem as características bioquímicas dos leitões.
\end{abstract}

Palavras-chave: suíno, desempenho, avilamicina, mananoligossacarídeo, Saccharomyces cerevisae

\begin{abstract}
The experiment was conducted to evaluate the performance and biochemical parameters in weaned piglets using alternative supplements to replace antibiotics. A total of 480 male pigs were used, randomly distributed in delineation with five treatments. The feed was based on corn, soybean meal and a commercial core for piglets. The treatments were T1: diet without supplements or basal diet, T2: basal diet with antibiotics, T3: basal diet with added probiotic, T4: basal diet with added probiotic and T5: basal diet with addition of symbiotic. In the experiment we evaluated performance characteristics, body weight, weight gain, feed intake and feed conversion. In the second part of the experiment, we evaluated the biochemical parameters of piglets used in the first experiment, fifty blood samples, ten samples of each treatment, were taken, and after separation of the clot, the serum was frozen at $-20^{\circ} \mathrm{C}$. Subsequently we analyzed the serum levels of total protein, albumin, globulin, albumin/globulin, ALP, creatinine, alanine aminotransferase, aspartate aminotransferase, gamma glutamyltransferase, cholesterol, urea, calcium, phosphorus and calcium/phosphorus ratio. No significant differences in biochemical parameters or in the performance of piglets submitted to different diets were found.
\end{abstract}

Keywords: swine, performance, avilamycin, mananoligossacharid, Saccharomyces cerevisiae

Recebido em 25 de agosto de 2011

Aceito em 4 de setembro de 2012

Apoio financeiro: FAPEMAT

E-mail: caramori@ufmt.br 


\section{INTRODUÇÃO}

O uso de antimicrobianos como promotores do crescimento na alimentação animal tem proporcionado diminuição nos custos de produção e uma melhora considerável no desempenho animal. Porém, seu uso vem sendo proibido em diversos países, devido a problemas e riscos que podem causar à saúde pública, e, em função dessa restrição, têm-se buscado alternativas viáveis aos antimicrobianos promotores do crescimento. Outro fator importante é que, há muitos anos, a avaliação da composição bioquímica do sangue é usada principalmente vinculada à patologia clínica em casos individuais. Payne et al. (1987) relataram que, desde o início da década de 70, essa prática laboratorial tem ampliado sua participação na rotina diagnóstica, mediante a difusão do conceito de perfil metabólico, isto é, o emprego de análise de componentes sanguíneos aplicada não somente a indivíduos, mas a rebanhos e populações de animais.

Por outro lado, a busca por aditivos promotores de crescimento que substituíram os antimicrobianos tem-se tornado objeto de pesquisas mais recentes, visto que os antimicrobianos podem trazer consequências negativas para a saúde pública.

Alguns autores, como Utiyama (2004), verificaram que a adição de mananoligossacarídeo proporcionou um desempenho semelhante aos aditivos antimicrobianos (promotores de crescimento). Isto mostra que os antimicrobianos podem ser substituídos, sem maiores prejuízos, na produção animal. Assim, cresce a necessidade de pesquisas sobre potenciais aditivos que substituam os aditivos antimicrobianos sem comprometer a eficiência e o custo-benefício na produção animal (Caramori Júnior, 2001; Utiyama, 2004).

A substituição dos promotores de crescimento convencionais, na ração de suínos, por aditivos prebióticos, probióticos e simbióticos deve ser adequadamente avaliada, uma vez que esses animais não necessariamente precisam se sobressair com melhores resultados e índices zootécnicos, e sim mostrar o mesmo desempenho, não alterando o custo de produção e, ainda, sem que se apresentem os inconvenientes dos antibióticos, proporcionando a mesma eficiência e produtividade animal sem oferecer risco alimentar nem de saúde pública.

Este trabalho teve o objetivo de avaliar o desempenho produtivo de leitões desmamados, bem como o desempenho metabólico e de funções orgânicas, por meio de mensuração de 14 marcadores bioquímicos séricos de leitões quando estes foram submetidos a diferentes dietas com e sem inclusão de antibiótico e de aditivos alternativos (probióticos, prebióticos e simbióticos).

\section{MATERIAL E MÉTODOS}

O experimento foi realizado no período de maio a junho de 2010. Utilizaram-se 480 leitões, machos castrados, desmamados com 21 dias de idade e da mesma linhagem. Antes de alojar os animais, a creche foi limpa e desinfetada, permanecendo por um período de sete dias em vazio sanitário. Após a desmama, os animais foram transferidos para as salas de creche, num galpão de alvenaria de aproximadamente $160 \mathrm{~m}^{2} /$ cada uma, com ambiente semicontrolado por meio de cortinas em toda extensão da altura e comprimento da sala em ambos os lados, possuindo cobertura de telhas de barro, com piso de concreto, sem forro, pé direito de $3,20 \mathrm{~m}$, em gaiolas metálicas suspensas medindo $1,80 \mathrm{~m} \mathrm{x}$ $2,00 \mathrm{~m}\left(3,6 \mathrm{~m}^{2} /\right.$ cada uma) com laterais, e piso parcial, de grade metálica, dotada de comedouro coletivo na extensão da lateral da baia e bebedouros tipo chupeta. Os leitões foram alojados no galpão de creche em duas salas, cada uma com 24 gaiolas coletivas suspensas do chão, com capacidade para 10 leitões por gaiola. Entre as gaiolas foram colocadas divisórias de ferro para que os leitões de tratamentos diferentes não entrassem em contato uns com os outros. Foi utilizado o delineamento inteiramente ao acaso, com cinco tratamentos, sendo o tratamento testemunha (dieta basal) com 16 repetições e os demais tratamentos com oito repetições por tratamento, totalizando 48 parcelas experimentais de 10 leitões cada. Houve a possibilidade de se ter o tratamento da dieta basal com 16 repetições, em razão do número de baias da sala e do número de leitões disponibilizados.

Os tratamentos foram: controle (dieta basal); dieta basal + antibiótico (avilamicina 100ppm); dieta basal + probiótico (à base de Saccharomyces cerevisae 2000ppm); 
dieta basal + prebiótico (mananoligossacarídeo $1000 \mathrm{ppm}$ ); dieta basal + simbiótico 3000ppm (Saccharomyces cerevisae 2000ppm + mananoligossacarídeo 1000ppm). Os animais receberam dietas experimentais isocalóricas e isoproteicas, formuladas para atender às exigências nutricionais dos leitões no período de creche - 21 a 65 dias - segundo o manual da linhagem genética, por se tratar de uma granja de reprodutores suídeos certificada (GRSC).

A composição nutricional da dieta basal está apresentada na Tab. 1

Tabela 1. Composição percentual e calculada das dietas basais nas fases pré-inicial 1 (PI 1), pré-inicial 2 (PI 2), inicial 1 (I 1) e inicial 2 (I 2), para leitões desmamados

\begin{tabular}{lllll}
\hline Ingrediente (\%) & PI 1 & PI 2 & I 1 & I 2 \\
\hline Milho grão & 21,80 & 32,40 & 42,00 & 55,75 \\
Nc.L. Aurotron 600 & 60,00 & & & \\
Nc.L. Aurotron 400 & & 40,00 & & \\
Nc.L. Aurotron 250 & & & 25,00 & 5,00 \\
Nc.L. Aurotron 50 & 4,00 & & & \\
Óleo de soja & 11,20 & 20,80 & 25,70 & 30,00 \\
Farelo de soja 46\% PB & 1,00 & 2,00 & 3,00 & 4,00 \\
Açúcar & 2,00 & 2,00 & 2,00 & 2,00 \\
Nc. En. Suínos (100kg/t) & & & & 0,05 \\
L-Lisina 78\% & 100,00 & 100,00 & 100,00 & 100,00 \\
\hline Batida total & Pi 1 & Pi 2 & i 1 & i 2 \\
\hline Nutriente & 19,81 & 20,03 & 20,08 & 19,10 \\
\hline Proteína bruta \% & 6,62 & 6,78 & 6,30 & 6,27 \\
Extrato etéreo \% & 1,92 & 2,39 & 2,58 & 2,73 \\
Fibra bruta \% & 6,87 & 6,34 & 6,16 & 6,90 \\
Cinza \% & 0,85 & 0,79 & 0,76 & 0,80 \\
Cálcio \% & 0,70 & 0,68 & 0,64 & 0,65 \\
Proteína total \% & $3.452,86$ & $3.452,09$ & $3.434,41$ & $3.407,73$ \\
Energia metabolizável kcal/kg & 1,54 & 1,43 & 1,33 & 1,22 \\
Lisina total \% & & & & \\
\hline
\end{tabular}

*Núcleo Aurotron 600: Fe 396,98mg; Mn 121,34mg; Zn 4454,38mg; Cu 245,69mg; iodo 1,69mg; Se 1,46mg; vit. A $10.800 \mathrm{UI}$; vit. $\mathrm{D}_{3} 2.250 \mathrm{UI}$; vit. E $45 \mathrm{mg}$; vit. $\mathrm{K}_{3} 3,60 \mathrm{mg}$; vit. $\mathrm{B}_{1} 1,80 \mathrm{mg}$; vit. $\mathrm{B}_{2} 7,56 \mathrm{mg}$; vit. $\mathrm{B}_{6} 3,60 \mathrm{mg}$; vit. $\mathrm{B}_{12}$ $27 \mathrm{mcg}$; biotina 126mcg; colina 502,26mg; metionina 5,34g; lisina 17,30g; antioxidante 224,85mg; sódio 5,96g; ácido fólico 0,63mg; ácido pantotênico 2,16mg; niacina 54mg. *Núcleo Aurotron 400: Fe 215,05mg; Mn 182,19mg; Zn $6.655,50 \mathrm{mg}$; $\mathrm{Cu} 361,06 \mathrm{mg}$; iodo 2,25mg; Se 0,68mg; vit. A $13.500 \mathrm{UI}$; vit. $\mathrm{D}_{3} 2.812,50 \mathrm{UI}$; vit. E 56,26mg; vit. $\mathrm{K}_{3}$ $4,50 \mathrm{mg}$; vit. $\mathrm{B}_{1} 2,25 \mathrm{mg}$; vit. $\mathrm{B}_{2} 9,45 \mathrm{mg}$; vit. $\mathrm{B}_{6} 4,50 \mathrm{mg}$; vit. $\mathrm{B}_{12} 33,75 \mathrm{mcg}$; biotina $157 \mathrm{mcg}$; colina $1.665 \mathrm{mg}$; metionina 7,06g; lisina 16,80g; antioxidante 337,56mg; Sódio 5,85g; ácido fólico 4,21 mg; ácido pantotênico $27 \mathrm{mg}$; niacina 67,50mg. *Núcleo Aurotron 250: Fe 344,09mg; Mn 215,53mg; Zn 7.818,34mg; Cu 577,69mg; iodo 3,6mg; Se $1,08 \mathrm{mg}$; vit. A $21.600 \mathrm{UI}$; vit. $\mathrm{D}_{3} 4500 \mathrm{UI}$; vit. $\mathrm{E} 90 \mathrm{mg}$; vit. $\mathrm{K}_{3} 7,2 \mathrm{mg}$; vit. $\mathrm{B}_{1} 3,60 \mathrm{mg}$; vit. $\mathrm{B}_{2} 15,12 \mathrm{mg}$; vit. $\mathrm{B}_{6}$ $7,20 \mathrm{mg}$; vit. $\mathrm{B}_{12} 54 \mathrm{mcg}$; biotina $252 \mathrm{mcg}$; colina $381,87 \mathrm{mg}$; metionina $6,99 \mathrm{~g}$; lisina $17,26 \mathrm{~g}$; antioxidante $395,77 \mathrm{mg}$; sódio 8,10g; ácido fólico 6,81mg; ácido pantotênico 43,20mg; niacina 108mg. *Núcleo Aurotron 50: Fe 1.796mg; Mn 1,077mg; Zn 2.700mg; Cu 3.776mg; iodo $18 \mathrm{mg}$; Se 5,40mg; vit. A $108.000 U I$; vit. $\mathrm{D}_{3} 22.500 \mathrm{UI}$; vit. E $450 \mathrm{mg}$; vit. $\mathrm{K}_{3} 36 \mathrm{mg}$; vit. $\mathrm{B}_{1} 18 \mathrm{mg}$; vit. $\mathrm{B}_{2} 75,60 \mathrm{mg}$; vit. $\mathrm{B}_{6} 36 \mathrm{mg}$; vit. $\mathrm{B}_{12} 270 \mathrm{mcg}$; biotina $1.260 \mathrm{mcg}$; colina $2.079 \mathrm{mg}$; metionina $15,70 \mathrm{~g}$; lisina $35 \mathrm{~g}$; antioxidante $200 \mathrm{mg}$; sódio $34,20 \mathrm{~g}$; ácido fólico $6,30 \mathrm{mg}$; ácido pantotênico $216 \mathrm{mg}$; niacina 540mg.

Às dietas basais, foram incluídos os aditivos conforme cada tratamento, sendo $100 \mathrm{~g}$ de avilamicina/ton (T2), 2,0kg de Saccharomyces cerevisae/ton (T3), 1,0kg de mananoligossacarídeo/ton (T4) e 3,0kg/ton de simbiótico (2,0kg/ton de Saccharomyces cerevisae $+1 \% \mathrm{~kg} / \mathrm{ton}$ de mananoligossacarídeo
- T5), sendo que T1 é somente a ração basal (controle negativo).

As rações foram formuladas pela empresa Seara Alimentos S/A, que estabeleceu quatro programas nutricionais, em função da idade dos leitões, sendo: pré-inicial 1 (PI 1), de 21 a 28 dias idade; pré-inicial 2 (PI 2), de 28 a 35 dias de 
idade; inicial 1 (I 1), de 35 a 46 dias de idade; e inicial 2 (I 2), de 46 a 64 dias de idade. Avaliaram-se o ganho médio de peso, o consumo médio de ração e a conversão alimentar em cada programa nutricional, além de 14 variáveis bioquímicas séricas por tratamento, do sangue coletado no $64^{\circ}$ dia de idade.

O ganho médio de peso foi obtido por meio da pesagem dos animais no início e no final de cada programa nutricional. O consumo médio de ração, para cada parcela experimental, foi calculado de acordo com cada programa nutricional, pela diferença do peso da ração, fornecida no início, e da sua sobra, no final do período de cada programa nutricional. A conversão alimentar foi calculada pela relação entre o consumo de ração e o ganho de peso de cada período.

Para avaliação das características bioquímicas, a coleta de sangue dos leitões foi realizada, aleatoriamente, em 10 animais por tratamento, ao término do experimento, por punção da veia jugular, perfazendo o total de 50 amostras séricas. Após a coagulação, o sangue foi submetido à centrifugação, 5.000 x g/3 min, para clareamento e sedimentação celular, e o soro foi acondicionado em frascos eppendorf identificados, congelados a $-20^{\circ} \mathrm{C}$ em freezer.

Determinaram-se em cada amostra as concentrações séricas de: proteína total (PT), albumina (Alb), globulina (Glob) - calculada pela diferença entre a proteína total e a albumina, relação albulmina:globulina (relação A:G), ureia, creatinina (Creat); colesterol $(\mathrm{Col})$, cálcio total (Ca); fósforo (P), relação cálcio:fósforo (relação Ca:P), alanina aminotransferase (ALT), aspartato aminotransferase (AST), gama- glutamiltransferase (GGT) e fosfatase alcalina (FA).

Foi empregado o método colorimétrico para a determinação da proteína total, com o reagente do biureto, e também para a albumina, em que o reagente utilizado foi o verde de bromocresol. Para determinação da ureia, foi usado o método enzimático cinético UV, e da creatinina, o do picrato alcalino. O colesterol foi determinado pelo método enzimático de Trinder, o cálcio pela cresolftaleína complexona (CPC), o fósforo através da metodologia cinética UV. Para a determinação da ALT e do AST, utilizou-se o método cinético UV-IFCC, da GGT, método Szasz modificado, e da FA, o método cinético optimizado (IFCC).

Valores de globulina foram obtidos da diferença entre proteína total e albumina, e as relações Alb:Glob e Ca:P foram obtidas pela relação matemática simples entre as respectivas variáveis.

As análises foram processadas colorimetricamente em analisador automático (ChemWell ${ }^{\circledR}$ Awareness Technology Inc.), utilizando-se kits comerciais (Labtest Diagnóstica ${ }^{\circledR}$, Minas Gerais, Brasil). Na análise estatística, realizada por meio de análise de variância, utilizou-se o SAEG (Sistema ..., 2007).

\section{RESULTADOS E DISCUSSÃO}

Os resultados zootécnicos são apresentados nas Tab. 2, 3, 4 e 5, onde são mostrados dados como peso inicial, peso final, ganho de peso total e conversão alimentar. $\mathrm{Na}$ Tab. 2, observa-se que não houve significância estatística entre os tratamentos para nenhuma das variáveis estudadas.

Tabela 2. Valores médios ( $\mathrm{kg}$ ) de peso corporal aos 21 dias de idade (PC), ganho de peso (GP), consumo de ração pré-inicial 1 (CRPI 1) e conversão alimentar (CA) no período de 21 a 28 dias de idade dos leitões em função dos diferentes tratamentos

\begin{tabular}{lllll}
\hline Tratamento & PC & GP & CRPI 1 & CA \\
\hline Controle & 6,27 & 1,38 & 19,48 & 1,59 \\
Antimicrobiano & 6,49 & 1,45 & 18,87 & 1,49 \\
Prebiótico & 6,34 & 1,52 & 19,65 & 1,47 \\
Probiótico & 6,26 & 1,54 & 20,46 & 1,43 \\
Simbiótico & 6,50 & 1,74 & 19,58 & 1,20 \\
\hline CV \% & 6,73 & 24,76 & 5,62 & 26,19 \\
\hline Média geral & 6.35 & 1.51 & 19.59 & 1.46 \\
\hline
\end{tabular}

Não houve diferença significativa entre os tratamentos pelo teste de Fischer com 5\% de probabilidade. 
Comportamento similar também foi observado por Santos (1998) quando comparou o fornecimento de antibiótico e probiótico composto por Lactobacillus sp. para leitões nas fases de aleitamento e creche. $\mathrm{Na}$ fase inicial de crescimento, Ko et al. (2000) também não observaram diferença no desempenho de suínos alimentados com três tipos diferentes de aditivos de ração (adição de 0,04\% de clortetraciclina, adição de $0,1 \%$ de mananoligossacarídeo e ração isenta de promotores de crescimento).
Na Tab. 3, de acordo com o programa nutricional na fase da ração pré-inicial 2, não houve diferença $(\mathrm{P}>0,05)$ entre os diferentes aditivos de ração com relação ao desempenho produtivo. Semelhantes resultados obtiveram Mikkelsen et al. (2003) que, ao compararem a utilização de prebióticos antimicrobianos como promotores de crescimento para leitões desmamados, não verificaram diferenças significativas quanto ao desempenho.

Tabela 3. Valores médios ( $\mathrm{kg}$ ) de peso corporal aos 28 dias de idade (PC), ganho de peso (GP), consumo de ração pré-inicial 2 (CRPI 2) e conversão alimentar (CA) no período de 28 a 35 dias de idade dos leitões em função dos diferentes tratamentos

\begin{tabular}{lllll}
\hline Tratamento & PC & GP & CRPI 2 & CA \\
\hline Controle & 7,66 & 2,87 & 27,93 & 1,05 \\
Antimicrobiano & 7,94 & 3,22 & 26,93 & 0,93 \\
Prebiótico & 7,89 & 3,02 & 28,56 & 0,98 \\
Probiótico & 7,78 & 2,92 & 27,25 & 1,02 \\
Simbiótico & 8,24 & 2,67 & 28,87 & 1,14 \\
\hline CV \% & 6,40 & 12,63 & 5,72 & 17,96 \\
\hline Média geral & 7.86 & 2,93 & 27,85 & 1,03 \\
\hline
\end{tabular}

Não houve diferença significativa entre os tratamentos pelo teste de Fischer com 5\% de probabilidade.

Ko et al. (2000), no entanto, ao avaliarem o desempenho de suínos em fase do desmame até a saída da creche, verificaram que os leitões do grupo-controle apresentaram menor diferença quanto ao ganho diário de peso e menor consumo diário de ração em relação aos animais que receberam prebiótico.

Ao avaliar a digestibilidade de dietas com a adição de 0,3\% de mananoligossacarídeo (MOS), em leitões na fase de creche, Utiyama (2004) verificou que esse aditivo nessa porcentagem proporcionou desempenho equivalente ao tratamento antimicrobiano dos 21 aos 35 dias de idade e não melhorou a conversão alimentar. Semelhantes resultados foram obtidos no presente estudo.

Observa-se, na Tab. 4, que, no período em que os leitões receberam a ração inicial 1 (35 a 46 dias), estes não mostraram diferença $(\mathrm{P}>0,05)$ entre os aditivos (probióticos, prebiótcos, simbióticos e antimicrobianos) quanto ao desempenho produtivo.

Tabela 4. Valores médios (kg) de peso corporal aos 35 dias de idade (PC), ganho de peso (GP), consumo de ração inicial 1 (CRI 1) e conversão alimentar (CA) no período de 35 a 46 dias de idade dos leitões em função dos diferentes tratamentos

\begin{tabular}{lllll} 
Tratamento & PC & GP & CRI 1 & CA \\
\hline Controle & 10,52 & 6,26 & 76,08 & 1,37 \\
Antimicrobiano & 11,16 & 6,59 & 74,55 & 1,29 \\
Prebiótico & 10,81 & 5,94 & 76,75 & 1,46 \\
Probiótico & 10,80 & 6,48 & 75,91 & 1,29 \\
Simbiótico & 10,91 & 6,24 & 75,82 & 1,30 \\
\hline CV \% & 6,52 & 21,20 & 8,70 & 30,68 \\
\hline Média geral & 10,78 & 6,30 & 75,87 & 1,35 \\
\hline
\end{tabular}

Não houve diferença significativa entre os tratamentos pelo teste de Fisher com 5\% de probabilidade. 
Todavia, Gebbink et al. (1999), ao avaliarem o desempenho produtivo de leitões em fase de creche, sob condição de alto desafio sanitário, observaram que os leitões que receberam rações com a adição de $5 \%$ de frutoligossacarídeo apresentaram melhor conversão alimentar quando comparados com aqueles que receberam a adição de $0,05 \%$ de virginamicina. Davis et al. (2002) observaram um aumento no ganho diário de peso em fases de crescimento e terminação de leitões que consumiram rações adicionadas de mananoligossacarídeo, em relação ao grupocontrole.

Rekiel et al. (2005) e Campbell et al. (2006) afirmaram, em suas pesquisas com suínos na fase de crescimento e terminação, não encontrar resultados diferentes após a utilização de aditivos promotores de crescimento prebióticos e antibióticos, em nenhuma das fases estudadas. Porém, esses autores observaram que houve redução da população de E.coli e aumento da população de bifidobactérias no cólon distal dos leitões tratados com frutoligossacarídeos em relação ao tratamento com antibiótico e ao grupo-controle, o que indica que este prebiótico interferiu na modulação benéfica da microbiota, contribuindo para um ambiente intestinal mais favorável aos processos digestivos.

Estudos quantitativos como os de Brendemuhl e Harvey (1999) também relatam dados importantes, pois esses autores, ao fornecerem $0,2 \%$ de mananoligossacarídeo como aditivo de ração de leitões desmamados, observaram maiores ganho médio diário de peso e consumo médio diário de ração, em comparação com a adição de $0,1 \%$ desse prebiótico.

$\mathrm{Na}$ Tab. 5, observa-se que não houve diferenças $(\mathrm{P}>0,05)$ no ganho de peso, no consumo de ração inicial 2 e na conversão alimentar dos leitões submetidos a rações com adição de antibiótico ou com aditivos alternativos (prebióticos, probióticos e simbióticos), no período de 46 a 64 dias de idade. Talvez seja a situação de baixo desafio, que normalmente se encontra em uma granja GRSC, razão para não haver diferenças entre os tratamentos aditivos.

Tabela 5. Valores médios (kg) de peso corporal aos 46 dias de idade (PC), ganho de peso (GP), consumo de ração inicial 2 (CRI 2), conversão alimentar (CA), no período de 46 a 64 dias de idade, e do peso corporal final, aos 64 dias de idade $\left(\mathrm{PC}_{\mathrm{f}}\right)$ dos leitões em função dos diferentes tratamentos

\begin{tabular}{lccccc}
\hline Tratamento & PC & GP & CRI $~$ & CA & PC $_{\mathrm{f}}$ \\
\hline Controle & 16,78 & 10,83 & 170,24 & 1,69 & 27,61 \\
Antimicrobiano & 17,75 & 10,95 & 166,09 & 1,83 & 28,71 \\
Prebiótico & 17,28 & 11,33 & 154,05 & 1,50 & 27,95 \\
Probiótico & 16,74 & 10,67 & 172,36 & 1,74 & 28,07 \\
Simbiótico & 17,15 & 10,52 & 156,81 & 1,69 & 27,67 \\
\hline CV \% & 9,97 & 22,55 & 10,80 & 24,12 & 7,27 \\
\hline Média geral & 17,08 & 10,86 & 166,13 & 1,69 & 27,94 \\
\hline
\end{tabular}

Não houve diferença significativa entre os tratamentos pelo teste de Fisher com 5\% de probabilidade.

Na Tab. 6, estão os resultados das características bioquímicas de leitões machos desmamados, submetidos a diferentes tratamentos, aos 64 dias de idade.

Estes resultados são similiares aos obtidos por Santos (2002), que também não verificou diferença entre os tratamentos com adição de manose $(0,0 \% 0,02 \% ; 0,1 \%$ e $0,2 \%)$ e aditivos antimicrobianos (25ppm de colistina) em rações para leitões de 21 a 60 dias de idade, com relação ao desempenho produtivo.

Não houve diferença $(\mathrm{P}>0,05)$ entre os valores dos parâmetros bioquímicos séricos analisados dos leitões submetidos a diferentes tratamentos aditivos. Semelhantes resultados encontrou Arantes (2002), em suas pesquisas com leitões desmamados, alimentados com dietas submetidas a diferentes níveis de zinco (zero, 1.500, 3.000 e $4.500 \mathrm{ppm}$ ) adicionados à ração. 
Desempenho e características bioquímicas...

Tabela 6. Valores médios de parâmetros bioquímicos séricos de leitões aos 64 dias de idade, submetidos a diferentes tratamentos

\begin{tabular}{llllllll}
\hline Parâmetros & Basal & Antibio & Probio & Prebio & Simbio & Média+DP* & CV\% \\
\hline PT (g/dL) & 5,65 & 5,58 & 5,70 & 5,47 & 5,33 & $5,55 \pm 0,63$ & 11,62 \\
Alb (g/dL) & 3,46 & 3,32 & 3,48 & 3,18 & 3,35 & $3,36 \pm 0,48$ & 14,55 \\
Glob (g/dL) & 2,19 & 2,25 & 2,22 & 2,28 & 1,98 & $2,18 \pm 0,47$ & 22,02 \\
Relação alb/glob & 1,65 & 1,54 & 1,60 & 1,51 & 1,80 & $1,62 \pm 0,44$ & 27,96 \\
Ca (mg/dL) & 8,88 & 9,04 & 8,73 & 8,73 & 8,56 & $8,79 \pm 0,81$ & 9,53 \\
P (mg/dL) & 12,92 & 11,61 & 12,59 & 14,00 & 13,38 & $12,89 \pm 2,63$ & 20,32 \\
Relação Ca/P & 0,70 & 0,79 & 0,73 & 0,64 & 0,67 & $0,70 \pm 0,13$ & 18,10 \\
Col (mg/dL) & 86,91 & 84,50 & 88,01 & 90,94 & 82,50 & $86,60 \pm 13,60$ & 16,08 \\
Creat (mg/dL) & 0,72 & 0,94 & 1,00 & 0,91 & 0,98 & $0,92 \pm 0,25$ & 26,27 \\
Ureia (mg/dL) & 41,46 & 42,37 & 39,61 & 37,80 & 36,41 & $39,49 \pm 9,54$ & 24,65 \\
FA (UI/L) & 159,79 & 161,28 & 158,02 & 174,82 & 167,93 & $164,33 \pm 38,43$ & 24,19 \\
GGT (UI/L) & 41,07 & 39,96 & 32,91 & 38,67 & 34,17 & $37,17 \pm 10,55$ & 28,28 \\
AST (UI/L) & 110,75 & 78,00 & 113,50 & 119,55 & 103,22 & $105,06 \pm 61,50$ & 59,61 \\
ALT (UI/L) & 81,62 & 72,67 & 66,40 & 78,44 & 67,44 & $72,98 \pm 20,38$ & 27,99 \\
\hline
\end{tabular}

1.* Desvio-padrão. 2. Não houve diferença significativa entre os tratamentos pelo teste de Fisher ao nível de 5\% de probabilidade. Basal (dieta controle negativo), Ant (dieta basal + avilamicina), Prob (dieta basal + Saccharomyces cerevisae), Preb (dieta basal + Mos) e Simb (dieta basal + Saccharomyces cerevisae + Mos).

\section{CONCLUSÃO}

A adição de antibiótico, probiótico, prebiótico ou simbiótico na ração de leitões machos desmamados (21 aos 64 dias de idade) não influencia o desempenho e as características bioquímicas séricas.

\section{REFERÊNCIAS}

ARANTES, V.M. Níveis de zinco na dieta de leitões recém-desmamados sobre: desempenho, incidência e gravidade de diarreia, isolamento de $E$. coli, perfil de parâmetros sanguíneos e avaliação econômica. 2002. 81f. Tese (doutorado em zootecnia). Jaboticabal: Faculdade de ciências agrárias e veterinárias, Universidade Estadual Paulista.

BRENDEMUHL, J.H.; HARVEY, M.R. Evaluation of Bio-Mos (Mananoligosaccharide) in diets for pigs: I. growth performance response during nursery and growing-finishing phases. Gainnesville: University of Florida, 1999. (Report to Alltech).

CAMPBELL, A.J.; GARDINER, G.E.; LEONARD, F.C. et al. The effect of dietary supplementation of finishing pigs with organic acids or mannanoligosaccharide on the coliform, Lactobacillus and Bifidobacterium flora of the intestinal contents and faeces. The Pig J., v.57, p.90-104, 2006.

CARAMORI JÚNIOR, J.G. Efeito de probióticos e prebióticos na ração de frangos de corte sobre o desempenho, rendimento de carcaça, características químicas e presença de Salmonella spp na carne. 2001. 56p. TESE (Doutorado em Zootecnia) Universidade Estadual Paulista Júlio e Mesquita Filho (UNESP - Botucatu), São Paulo.
DAVIS, M.E.; MAXWELL, C.V.; BROWN, D.C. et al. Effect of dietary mannanoligosaccharides and (or) pharmacological additions of copper sulfate on growth performance and immunocompetence of weaning and growing/finishing pigs. J. Anim. Sci., v.80, p.28872894, 2002.

GEBBINK, G.A.R.; SUTTON, A.L.; RICHERT, B.T.; PATTERSON, J.A. et al. Effects of addition of fructooligosaccharide (FOS) and sugar beet pulp to weanling pig diets on performance, microflora and intestinal health. Swine Day Rep., 6p, 1999.

KO, T.G.; KIM, J.D.; HAN, Y.K. Study for the development of antibiotics-free diet for growing pigs. Korean J. Anim. Sci., v.42, p.45-54, 2000.

MIKKELSEN, L.L.; JAKOBSEN, M.; JENSEN, B.B. Effects of dietary oligosaccharides on microbial diversity and fructo-oligossaccharide degrading bacteria in faeces of piglets post weaning. Anim. Feed Sci. Tecnol., v.109, p.133-150, 2003.

PAYNE, J.M.; PAYNE, S. O teste do perfil metabólico. New York: Oxford University Press, 1987. 179p.

REKIEL, A.; WIECEK, J.; DZIUBA, M. Effect of feed additives on the results of fattening and selected slaughter and quality traits of pork meat of pigs with different genotypes. Czech J. Anim. Sci., v.50, p.561$567,2005$.

SANTOS, W.G. Manose na alimentação de leitões na fase de creche (Desempenho, parâmetros fisiológicos e microbiológicos). 2002. 66f. Dissertação (Mestrado em Zootecnia) - Universidade Federal de Lavras,Lavras, 2002. 
SANTOS, M.S. Probiótico à base de Lactobacilos para leitões na fase de aleitamento e de creche. 1998. 76f. Dissertação (Mestrado em Tecnologia de Alimentos) - Universidade Federal de Viçosa, Viçosa, 1998.

SISTEMA para análises estatísticas e genéticas SAEG. 2007. Viçosa, MG: UFV/CPD, 2007.
UTIYAMA, C.E. Utilização de agentes antimicrobianos, probióticos, prebióticos e extratos vegetais como promotores de crescimento de leitões desmamados. 2004. 110f. Tese (Doutorado em Agronomia). Escola Superior de Agricultura "Luiz de Queiroz" - USP, Piracicaba. 2004. 